\title{
Edge Deviation Analysis for Photochemical Machining of Copper
}

\author{
Chandrakant K. Vhare, Vikram R. Chavan, Amit A. Shinde, \\ Rameshwar D. Solage, Shashikant S. Jadhav
}

\begin{abstract}
Photochemical machining is broadly employed in the fabrication of components which are used in various fields like electronics, medical, biological, etc. Copper is one of the materials having various applications. The accuracy of the photochemically machined component is governed by edge deviation and it plays vital role in many small size components. This paper focusses on the edge deviation analysis for photochemically machined copper specimens. The experimentation has been performed for different concentrations for ferric chloride etchant. The analysis of the specimens has been carried out and the suitable parameters are predicted in the paper.
\end{abstract}

Index Terms-Photochemical machining, edge deviation, copper, concentration.

\section{INTRODUCTION}

The one of the widely used non-conventional machining process is the Photochemical machining (PCM) which is also called as photo etching or photochemical milling or photo fabrication. PCM employs chemical milling process for fabricating the components of sheet metals using a photoresist and etchants (solvents) to machine away selected areas corrosively [1].

\section{The Process:}

The photochemical machining process is briefed below [3-6]:

1. The procedure begins by printing the state of the part onto optically clear and dimensionally stable photographic film, known as photo tool.Simultaneously, cutting of the material into required size followed by cleaning of the material, is performed.

2. Then photoresist is plied to the metal or prepared specimen. Photoresist may be positive or negative.

3. Further, the specimen is exposed to source of UV (ultra violet) light.

4. After UV light exposure, the specimen is dipped in developer for specific time period. Developing will

Chandrakant K. Vhare, Assistant Professor, Department of Mechanical Engineering, SVERI's College of Engineering, Pandharpur, India.

Vikram R. Chavan, Assistant Professor, Department of Mechanical Engineering, SVERI's College of Engineering, Pandharpur, India.

Amit A. Shinde, Assistant Professor, Department of Mechanical Engineering, SVERI's College of Engineering, Pandharpur, India.

Rameshwar D. Solage, Assistant Professor, Department of Mechanical Engineering, SVERI's College of Engineering, Pandharpur, India.

Shashikant S. Jadhav, Assistant Professor, Department of Mechanical Engineering, SVERI's College of Engineering, Pandharpur, India. happen and the required area will be made open for etching in this stage.

5. Now, the specimen is subjected to etching where the material removal takes place through corrosion phenomenon. The etchants used are generally ferric chloride or cupric chloride.

6. Then, after achieving the required etching, the specimens are cleaned. The photoresist is stripped off from the specimens. Here, the required component is ready by using photochemical machining.

\section{Related Work:}

Various researchers have contributed in photochemical machining investigation for different materials and their parametric study. Ferric chloride $\left(\mathrm{FeCl}_{3}\right)$ is reported as the most widely used etchant for copper and its alloys in photochemical machining. The analysis for effect of control parameters on the performance parameters like material removal rate, undercut, surface roughness has been reported by researchers for the copper and its alloys like brass, german silver, etc. [3-6]. The photochemical machining study for the hard to cut materials like Inconel has been also reported [7-8]. The photochemical machining process has been applied for fabrication of components like microchannels, heat sinks, etc. [9-13]. In this paper, the analysis of photochemical machining for copper material is presented.

\section{Methodology}

Material:

Copper material has wide range of application in fabrication of micro components like micro heat exchangers, microchannels, molds for microchannels, etc. Therefore, Copper is selected as the material for analysis. The size of the copper specimen was $20 \mathrm{mmx} 20 \mathrm{mmx} 1 \mathrm{~mm}$ thk.

\section{Experimental Set-up:}

The experimental set up for photochemical machining is presented in Figure 1. Ferric chloride was used as the etchant. The etching temperature was kept constant as $50{ }^{\circ} \mathrm{C}(+/ 0.5$ ${ }^{\circ} \mathrm{C}$ ). The etching time was also kept constant as 15 minutes. The photo tool was prepared by taking print out on a transparent paper. The size of the component to be etched was $6.8 \mathrm{~mm}$ by $6.8 \mathrm{~mm}$. 


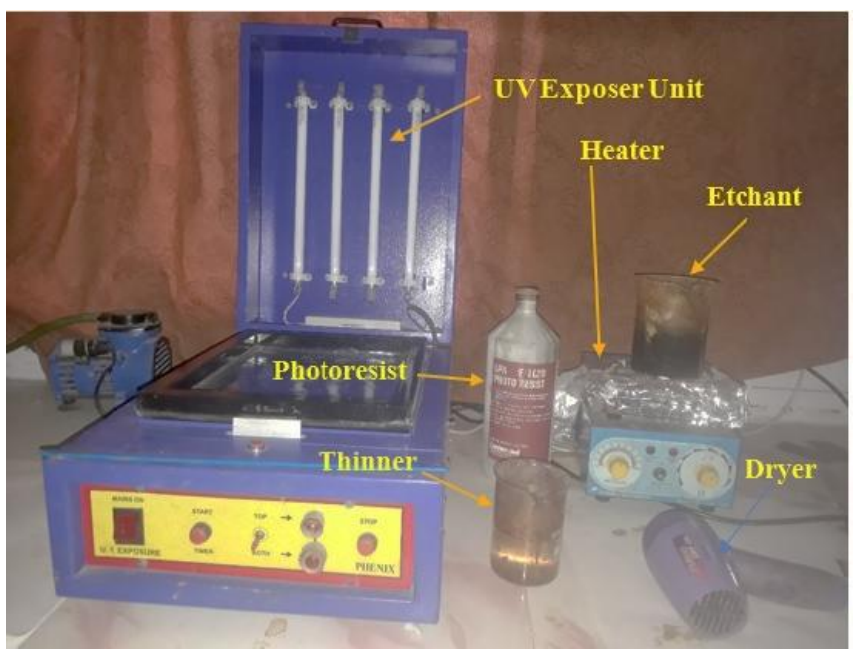

Figure 1: Experimental set up for PCM

The experimentation was carried out for analyzing the effect of concentration of etchant. The concentrations are varied from $300 \mathrm{~g} / \mathrm{L}$. to $700 \mathrm{~g} / \mathrm{L}$. with an interval of $100 \mathrm{~g} / \mathrm{L}$. The performance parameter was the edge deviation.

\section{RESUlTS AND DISCUSSION}

The photochemical machining has been carried out on copper specimen at different concentrations of ferric chloride i.e. $300 \mathrm{~g} / \mathrm{L}, 400 \mathrm{~g} / \mathrm{L}, 500 \mathrm{~g} / \mathrm{L}, 600 \mathrm{~g} / \mathrm{L}$, and $700 \mathrm{~g} / \mathrm{L}$. The dimensional analysis has been performed using RAPID I Vision 5 microscope. The specimen images for concentration $500 \mathrm{~g} / \mathrm{L}$ and $700 \mathrm{~g} / \mathrm{L}$ are depicted in Figure 2 (a) and (b), respectively. It is observed from the images that there is increase in dimensions (size of the specimen) and it is increasing with increase in concentration of the etchant. This is due to the formation of undercut during photochemical machining.

The deviation of edge from the required is one of the significant factors for the fabrication of micro components. Therefore, edge deviation always desired to be minimum The analysis for the edge deviation has also been performed by using the RAPID I Vision 5 microscope. The sample images for the edges (one edge) at different concentrations as 300 $\mathrm{g} / \mathrm{L}, 400 \mathrm{~g} / \mathrm{L}, 500 \mathrm{~g} / \mathrm{L}, 600 \mathrm{~g} / \mathrm{L}$, and $700 \mathrm{~g} / \mathrm{L}$ are presented in Figures 3 (a), (b), (c), (d), and (e), respectively. The average edge deviation is observed to be minimum at concentration level $300 \mathrm{~g} / \mathrm{L}$. The edge is noted to be increasing with increase in concentration and found to be maximum at concentration $700 \mathrm{~g} / \mathrm{L}$. This may be due to lesser attack of molecules on the edges of specimen at lesser concentration. As the concentration increases, the molecules present in the etchant increases. The greater number of molecules will attack on the edge for the fixed temperature and time. The material will be removed abruptly through diffusion at the edges and in turn, the edge deviation increases with increase in concentration.
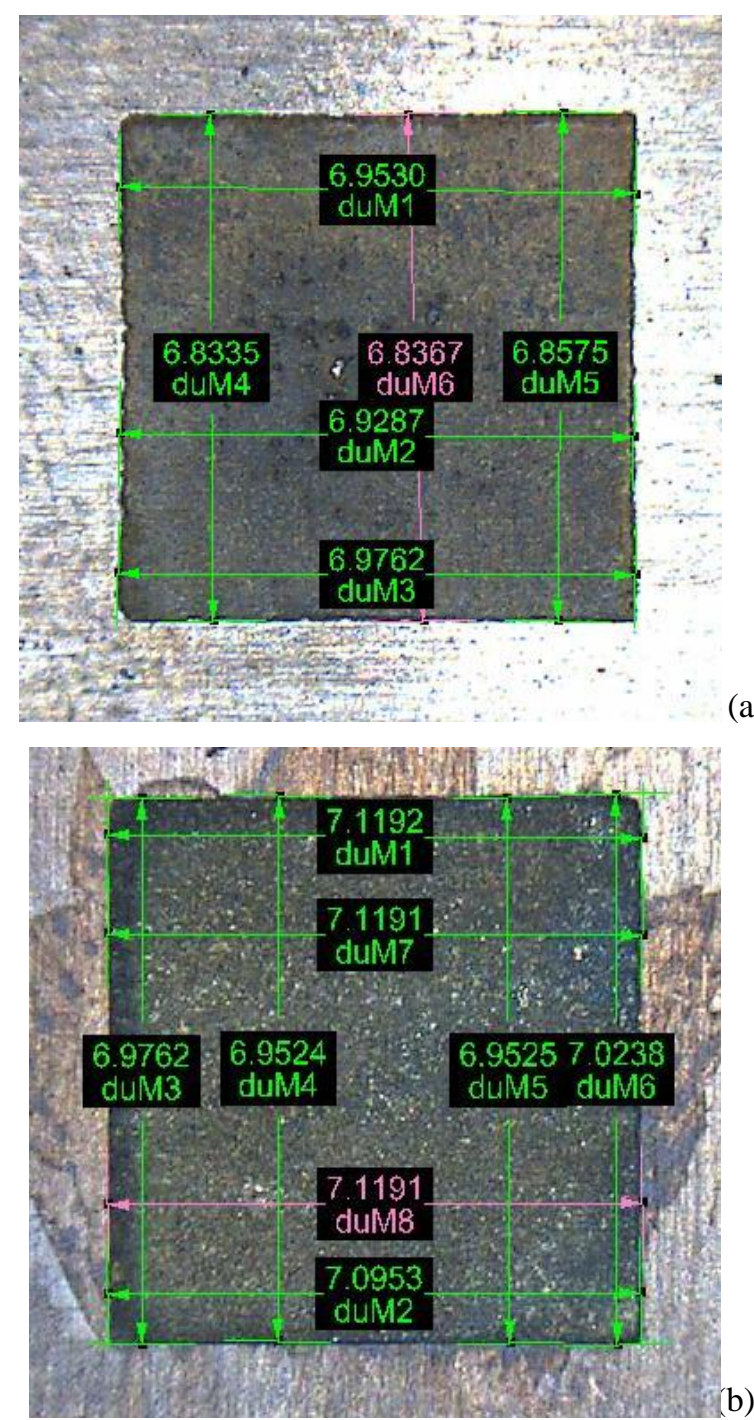

Figure 2: Dimensions of photochemically machined components at different concentrations (a) $500 \mathrm{~g} / \mathrm{L}$. (b) $700 \mathrm{~g} / \mathrm{L}$.
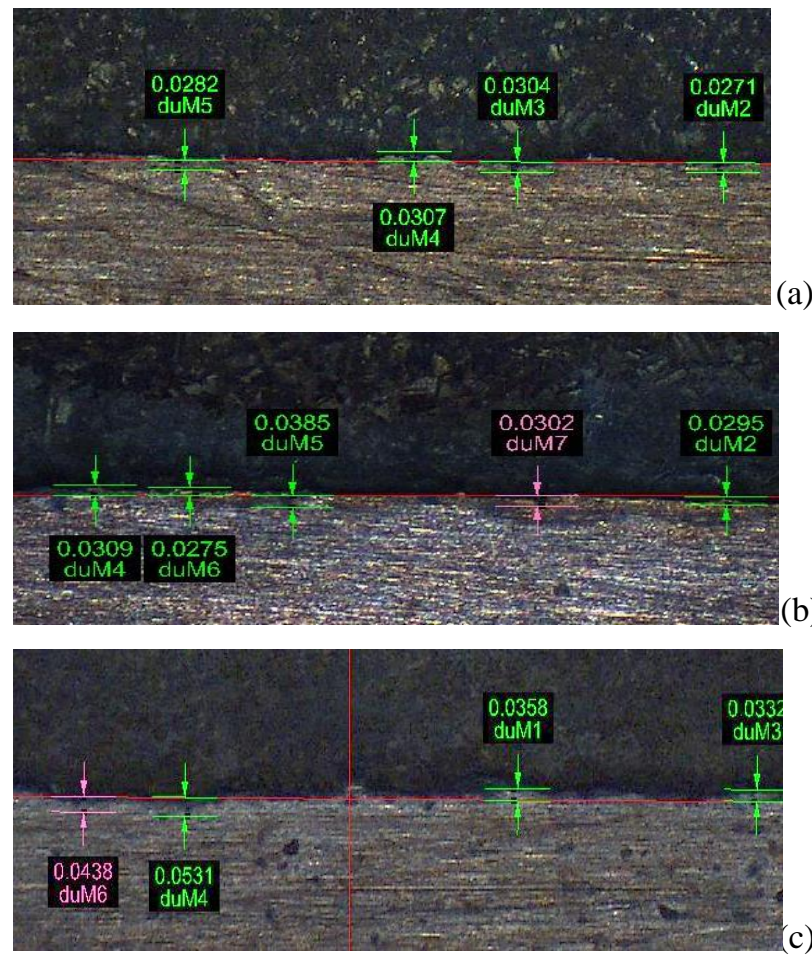


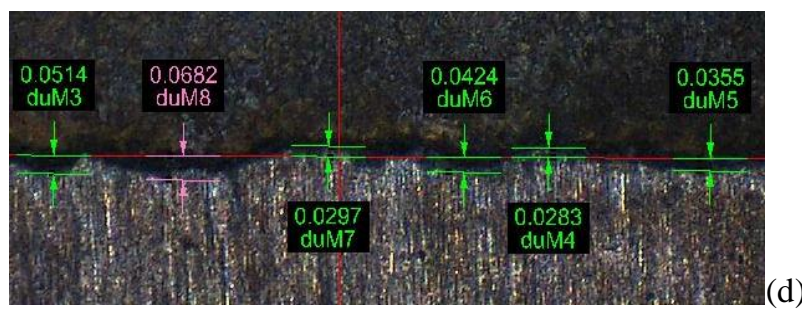

(d)

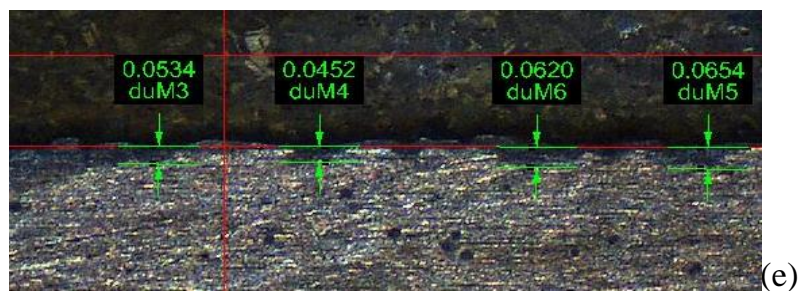

Figure 3: Edge deviation for photochemically machined components at different concentrations (a) $300 \mathrm{~g} / \mathrm{L}$, (b) $400 \mathrm{~g} / \mathrm{L}$, (c) $500 \mathrm{~g} / \mathrm{L}$. , (d) $600 \mathrm{~g} / \mathrm{L}$. , (e) $700 \mathrm{~g} / \mathrm{L}$.

\section{CONCLUSIONS}

The photochemical machining study for analysis of edge deviation for copper material performed. Ferric chloride is used as the etchant and effect of concentration on the edge deviation has been analyzed by keeping the other factors like temperature and etching time as constant. It is found that the dimensions of the photochemically machined component are greater than the desired dimensions of photo tool. The edge deviation is observed to be minimum for concentration of 300 $\mathrm{g} / \mathrm{L}$ and increases with increase in concentration up to 700 $\mathrm{g} / \mathrm{L}$ and noted maximum at concentration of $700 \mathrm{~g} / \mathrm{L}$.

\section{REFERENCES}

[1]. Allen DM (2004) Photochemical machining: from 'manufacturing's best kept secret' to a $\$ 6$ billion per annum, rapid manufacture process. CIRP Ann-Manuf Technol 53(2):559-572. Doi : 10. 1016/S0007-8506(07)60029-8

[2]. Yadav, R. P., \& Teli, S. N. (2014). A Review of issues in photochemical machining. International Journal of Modern Engineering Research, 4(7), 49-53.

[3]. Wangikar, S. S., Patowari, P. K., \& Misra, R. D. (2017). Effect of process parameters and optimization for photochemical machining of brass and german silver. Materials and Manufacturing Processes, 32(15), 1747-1755.

[4]. Wangikar, S. S., Patowari, P. K., \& Misra, R. D. (2016, December) Parametric Optimization for Photochemical Machining of Copper Using Grey Relational Method. In Techno-Societal 2016, International Conference on Advanced Technologies for Societal Applications (pp. 933-943). Springer.

[5]. Wangikar, S.S., Patowari, P.K., \& Misra, R.D. (2018). Parametric Optimization for Photochemical Machining of Copper using Overall Evaluation Criteria. Materials Today Proceedings. 5(2), 4736-4742, Doi :10.1016/j. matpr.2017.12.046

[6]. Wangikar, S. S., Patowari, P. K., Misra, R. D., \& Misal, N. D. (2019) Photochemical Machining: A Less Explored Non-Conventional Machining Process. In Non-Conventional Machining in Modern Manufacturing Systems (pp. 188-201). IGI Global.

[7]. Misal, N. D., \& Sadaiah, M. (2017). Investigation on Surface Roughness of Inconel 718 in Photochemical Machining. Advances in Materials Science and Engineering, 2017.
[8]. Misal, N. D., Saraf, A. R., \& Sadaiah, M. (2017). Experimental investigation of surface topography in photochemical machining of Inconel 718. Materials and Manufacturing Processes, 32(15), 1756-1763.

[9]. Wangikar, S. S., Patowari, P. K., \& Misra, R. D. (2018). Numerical and experimental investigations on the performance of a serpentine microchannel with semicircular obstacles. Microsystem Technologies. 24(8), 3307-3320.

[10]. Das, S. S., Tilekar, S. D., Wangikar, S. S., \& Patowari, P. K. (2017). Numerical and experimental study of passive fluids mixing in micro-channels of different configurations. Microsystem Technologies, 23(12), 5977-5988.

[11]. Chavan, N. V., Bhagwat, R. M., Gaikwad, S. S., Shete, S. S., Kashid, D. T., \& Wangikar, S. S. (2019). Fabrication \& Characterization of Microfeatures on PMMA Using CO2 Laser Machining.International Journal for Trends in Engineering and Technology. 36(1), 39-32.

[12]. Kulkarni, H. D., Rasal, A. B., Bidkar, O. H., Mali, V. H., Atkale, S. A. Wangikar, S. S., \& Shinde, A. B. (2019). Fabrication of Micro-Textures on Conical Shape Hydrodynamic Journal Bearing. International Journal for Trends in Engineering and Technology. 36(1), $37-41$

[13]. Raut, M. A., Kale, S. S., Pangavkar, P. V., Shinde, S. J., Wangikar, S. S., Jadhav, S. V., \& Kashid, D. T. (2019) Fabrication of Micro Channe Heat Sink by using Photo Chemical Machining. International Journal of New Technology and Research. 5(4), 72-75. 